\title{
Об одной библиографической химере: трактат Д. С. Аничкова в издании Н. И. Новикова
}

\section{Regarding a Bibliographic Chimera: N. I. Novikov's Publication of a Treatise by Dmitrii Anichkov}

\author{
А. В. Зайцева \\ Научная библиотека Московского государственного университета имени \\ М. В. Ломоносова \\ A. V. Zaitseva \\ Scientific Library of Moscow State University \\ anna.zaytseva.shesternina@gmail.com \\ А. Л. Лифшиц \\ Национальный исследовательский университет -Высшая школа \\ экономики \\ A. L. Lifshits \\ National Research University -Higher School of Economics \\ alifshits@hse.ru
}

\begin{abstract}
:
References to Dmitrii Anichkov's Annotationes in logicam, metaphysicam et cosmologiam (1782) regularly appear in literature on Russian book history. However, this publication not only did not exist, but could not exist. Anichkov, following the classification put forth by Christian Wolf and Friedrich Baumeister, regarded cosmology as part of metaphysics. In fact, Anichkov's textbook, entitled Annotationes in logicam et metaphysicam, which was published in 1782 and 1783, included two volumes that ontology and cosmology respectively. Both are yet to be explored.
\end{abstract}

Keywords:

Moscow University Typography, unknown edition, the history of education, textbook, philosophy, metaphysics

В ряде био- и библиографических справочников, а вслед за ними и в научной литературе встречается упоминание трактата профессора Московского университета Д. С. Аничкова (1733-1788) Annotationes in logicam, metaphysicam et cosmologiam, который во многих случаях датируется 1782 годом. ${ }^{1} \mathrm{~K}$ нашему

\footnotetext{
${ }^{1}$ См., например: Г. Н. Геннади, Справочный словарь о русских писателях и ученых, умерших в XVIII и XIX столетиях и Список русских книг с 1725 по 1825 г. Т. 1 (Берлин: тип. Розенталя и Кํ, 1876), 32. (G. N. Gennadi, Spravochnyi slovar' o russkikh pisateliakh i uchenukh, umershikh v XVIII i XIX stoletiiakh i spisok russkikh knig s 1725 po 1825 g. T. 1 (Berlin: tip. Rozentalia i K०, 1876), 32); С. А. Венгеров, Критико-библиографический словарь русских писателей и ученых (от начала русской образованности до наших дней), t. 1 (Санкт-Петербург: Семеновская Типо-литография И. Ефрона, 1889), 579. (S. A. Vengerov, Kritiko-bibliograficheskii slovar' russkikh pisatelei i uchenykh (ot nachala russkoi obrazovannosti do nashikh dnei) t. 1 (St. Petersburg: Semenovskaia tipo-litografiia I. Efrona, 1889), 759); Энциклопедический словарь, под ред. И. Е. Андреевского. Т. 1а (Санкт-Петербург: Ф. А. Брокгауз и И. А. Ефрон, 1890), 786. (Entsiklopedicheskii slovar' pod red. I. E. Andreevskogo T. 1а
} 
удивлению, обнаружить свидетельств о существовании экземпляров такой книги не удалось. Очевидно, авторы множества научных работ, учебных пособий и справочников, которые цитируют это произведение, полагались на предшественников и не проверяли, существует ли такое издание на самом деле. Похоже, авторитетным источником позднейших сведений стал “Биографический словарь профессоров и преподавателей Московского университета,” который называет Аничкова сочинителем этого труда. ${ }^{2}$

Такого издания не знает и Сводный каталог книг, напечатанных в России на иностранных языках. ${ }^{3}$ Зато под № 143 в нем приведено описание труда Аничкова с похожим названием: Annotationes in logicam et metaphysicam ..., ${ }^{4}$ Это издание, представляющее собой компиляцию из отрывков сочинений Фридриха Христиана Баумейстера (Friedrich Christian Baumeister; 1709-1785) и других европейских философов, а также комментариев к ним, хорошо знакомо библиографам и иным книжникам и легко находится в каталогах библиотек. Его иногда принимают за упомянутый трактат по логике, метафизике и космологии, ${ }^{5}$ хотя ни на титульном листе, ни в содержании ничего похожего на космологию не содержится.

Впрочем, сочинение под заглавием Annotationes in Cosmologiam существует в виде отдельного курьезного тома, не имеющего ни титульного листа, ни выходных данных. Именно так его описывает Систематический каталог книг

(St. Petersburg: F. A. Brokgauz і I. A. Efron, 1900), 786); Русский биографический словарь, t. 2 (СанктПетербург, 1900), 149. (Russkii biograficheskii slovar', t. 2 (St. Petersburg, 1900), 149); Т. В. Артемьева, История метафизики в России XVIII века, (Санкт-Петербург: Алетейя, 1996), 114. (Т. V. Artem'eva, Istoriia metafiziki v Rossii XVIII veka (St. Petersburg: Aleteiia, 1996), 114); и т.д.

2 Биографический словарь профессоров и преподавателей Императорского Московского университета за истекающее столетие со дня учреждения января 12-го 1755 года по день столетнего юбилея января 12-го 1855 года, составленный трудами профессоров и преподавателей, занимавших кафедры в 1854 году, и расположенный по азбучному порядку. Ч. 1 (Москва: Унив. Тип., 1855), 6. (Biograficheskii slovar' professorov i prepodavatelei Imperatorskogo Moskovskogo universiteta za istekaiushchee stoletie so dnia uchrezhdeniia ianvaria 12-go 1755 goda po den'stoletnego iubileia ianvaria 12-go 1855 goda, sostavlennyi trudavi professorov i prepodavatelei, zanimaiushchikh kafedry $v 1854$ godu, $i$ raspolozhennyi po azbuchnomu poriadku Ch.1 (Moscow: Univ. tip., 1855), 6).

${ }^{3}$ Сводный каталог книг на иностранных языках, изданных в России в XVIII веке, 17о1-18оо, t. 1-3 (Ленинград: Наука, Ленинградское отделение, 1984-1986). (Svodnyi katalog knig na inostrannykh iazykakh, izdannykh v Rossii v XVIII veke. 1701-180o, t. 1-3 (Leningrad: Nauka, Leningradskoe otdelenie, 1984-1986). Подобно всякому претендующему на полноту изданию, и этот каталог нуждается в дополнениях и корректировках.

${ }^{4}$ Annotationes in logicam et metaphysicam ex variis probatissimis auctoribus excerptae et usibus Rossicae juventutis una cum parte polemica et variis exercitationibus, ex logica disputatrice selectis, adornatae a collegiorum assessore, logices, metaphysices et matheseos purae in Universitate Imperiali Mosquensi professore publico ordinario Demetrio Anitschcow (Mosquae: Impensis N. Novicow et societatis: In Typographia Universitatis apud N. Novicow, 1782). На обороте титульного листа этого издания стоит издательская марка Новикова с латинскими литерами.

${ }^{5}$ См., например: М. В. Семиколенных, "Institutiones philosophiae rationalis Фридриха Христиана Баумейстера и некоторые из ранних российских учебников по логике”, Второй Международный Конгресс Русского общества истории и философии науки “Наука как общественное благо," t. 4 (Москва: РОИФН, 2020), 112-116. (М. V. Semikolennykh, "Institutiones philosophiae rationalis Fridrikha Khristiana Baumeistera i nekotorye iz rannikh rossiiskikh uchebnikov po logike," Vtoroi Mezhdunarodnyi Konhress Russkogo obshchestva istorii i filosofii nauki "Nauka kak obshchestvennoe blago" (Moscow: ROIFN, 2020), 112-116). 
библиотеки Киево-Печерской лавры. ${ }^{6}$ Четыре экземпляра книг, похожих на описанный том имеются в фонде Научной библиотеки МГУ. Судя по ним, издание имеет только шмуцтитул, на котором слова заглавия предваряются римской цифрой “II". То есть внешний вид книги указывает на ее несамостоятельность и заставляет искать первую часть.

Вероятно, это обстоятельство, а также наличие сведений о неких латинских “Прибавлениях ${ }^{7}$ к логике, метафизике и космологии," дали повод Н.Н. Мельниковой счесть книжку приложением к Annotationes Аничкова. ${ }^{8}$ Основанием для такого объединения могли также послужить наличие издательской марки Новикова ${ }^{9}$ на обороте шмуцтитула и сходство (но не тождественность) типографского оформления. При этом в старейшей служебной картотеке Научной библиотеки МГУ, составленной в XIX столетии, никакой связи с трудом Аничкова не обозначено, книги имеют шифры, относящие их к разным, хотя не слишком далеко отстоящим друг от друга разделам философии.

В издание, которое Н. Н. Мельникова сочла приложением к труду Аничкова, описано под редуцированным заглавием шмуцтитула Annotationes in cosmologiam. ${ }^{10}$ Тем не менее, экземпляры компиляции 1782 года из фондов Научной библиотеки МГУ показывают, что в издании труда Аничкова, при том же числе страниц, что и в описании в Сводном каталоге, нет шмуцтитула, в котором упоминалась бы космология. Нет его и в отсканированном экземпляре РГБ. ${ }^{11}$

В то же время в фондах библиотеки Московского университета есть издание, которое, несомненно, представляет собой первую часть анонимного трактата. ${ }^{12}$ Этот том также не имеет титульного листа, а на шмуцтитуле, его заменяющем, значится: Annotationes in metaphysicam, et quidem I. In Ontologiam. Особенности набора, расположение заглавий, стиль гравированных заставок и издательская марка Н.И. Новикова не оставляют сомнений в том, что две книжечки на латинском языке, напечатанные in octavo представляют собой двухтомник, вышедший из типографии Московского университета между 1779 и 1789 гг., в то время, когда типография, “осуществлявшая одновременно функции издательства,” стала играть заметную роль в распространении философских

\footnotetext{
${ }^{6}$ Систематический каталог книг Библиотеки Киево-Печерской лавры, t. 2 (Киев: Тип. КиевоПечерской Успенской лавры, 1912), № 7689. (Sistematicheskii katalog knig Biblioteki Kievo-Pecherskoi Uspenskoi lavry, t. 2 (Kyiv: Tip. Kievo-Pecherskoi Uspenskoi lavry, 1912), No. 7689).

7 Так слово annotationes переведено в цензорском разрешении профессора Антона Барсова на книге Аничкова 1782 г.; осознавая его условность, используем этот перевод.

${ }^{8}$ Н. Н. Мельникова, Издания, напечатанные в Типографии Московского университета, XVIII век. (Москва: Издательство Московского Университета, 1966), № 1471. (N. N. Mel'nikova, Izdaniia, napechatannye $v$ Tipografii Moskovskogo universiteta, XVIII vek (Moscow: Izdatel'stvo Moskovskogo Universiteta, 1966), No. 1471); петитом указано приложение с собственной пагинацией II. Annotationes in cosmologiam, 144.

9 Правда, в этом случае применена издательская марка с буками НН в круге.

${ }^{10}$ Сводный каталог, № 143. (Svodnyi katalog, №. 143).

${ }^{11}$ Annotationes in logicam et metaphysicam, Russian State Library, accessed February 7, 2021, https://dlib.rsl.ru/viewer/o1003497912\#?page=5.

12 Издание, представленное в двух экземплярах, имеет свой собственный шифр, и его связь с “Прибавлениям к космологии” эксплицитно никак не обозначена.
} 
знаний. ${ }^{13}$ Вероятно, именно этот двухтомник отражен, причем весьма причудливым образом, в каталоге библиотеки Московской Духовной академии. Здесь указано анонимное издание Annotationes in cosmologiam et metaphysicam, et quidem I in ontologiam. ${ }^{14}$

Все сказанное позволяет заключить, что мы имеем дело с библиографической путаницей, возникшей, очевидно, довольно давно и не проясненной до настоящего времени в том числе и из-за редкости анонимного двухтомника.

Обращение к книжным росписям показало, что оба тома засвидетельствованы один за другим в издававшемся Н. И. Новиковым списке книг 1784 года, ${ }^{15}$ а также в следующем году ${ }^{16}$ и в нескольких позднейших выпусках. Цена за первый том составляла 50 копеек без переплета и 65 копеек для издания в переплете; за второй, соответственно, 35 и 50 копеек. В каталоге за предшествующий 1783 год книжки еще не значатся, что означает выход книг из печати в 1783 или в начале 1784 года. Сплошной просмотр газеты “Московские ведомости” за 1783 год показал, что объявление о продаже первого тома было опубликовано 18 октября; ${ }^{17}$ а второго - 2 декабря. ${ }^{18}$ Заметим только, что латинская компиляция Аничкова, опубликованная в 1782, числится в "росписи" за 1783 год ${ }^{19}$ как самостоятельное издание, а не как первый том многотомного издания; название труда Аничкова здесь приведено полностью.

Таким образом, согласно шмуцтитулам и с учетом того, как анонимные книжки представлены в книгопродавческих росписях и объявлениях, они могут быть описаны следующим образом:

[Annotationes in metaphysicam. T. 1-2]. - [Москва: в Унив. тип., у Н. Новикова, 1783]. - $8^{\circ}$ (16 cм).

[T. 1]: Annotationes in metaphysicam, et quidem I. In Ontologiam. - 242 c.

[T. 2]: II. Annotationes in Cosmologiam. - 144 c.

Сверка текста компиляции Аничкова, его единственного известного труда на латинском языке, с текстом двухтомника ожидаемо не выявила совпадений. ${ }^{20} \mathrm{~B}$

\footnotetext{
${ }^{13}$ Артемьева, История метафизики, 119. (Artem'eva, Istoriia metafiziki, 119).

${ }^{14}$ Систематический каталог книг Библиотеки Московской духовной академии, составленный библиотекарем Московской духовной академии И. Корсунским, вып. 6. Философия (Москва: Тип. М. Н. Лаврова, 1890), 97, № 12363. (Sistematicheskii katalog knig Biblioteki Moskovskoi Dukhovnoi akademii, sostavlennyi bibliotekarem Moskovskoi Dukhovnoi akademii I. Korsunskim, vyp. 6. Filosofiia (Moscow: Tip. M. N. Lavrova, 1890), 97, No. 12363).

15 Роспись российским книгам, которые продаются без переплета и в разных переплетах в Университетской книжной лавке, что у Никольских ворот, в Москве (Москва: Унив. тип., у Н. Новикова, 1784), 57. (Rospis' rossiiskim knigam, kotorye prodaiuts'a bez perepleta $i v$ raznykh perepletakh $v$ Universitetskoi knizhnoi lavke, chto u Nikol'ckikh vorot, v Moskve (Moscow: Univ. tip., u N. I. Novikova, 1784), 57).

${ }^{16}$ Ibid, 100.

${ }^{17}$ Московские ведомости, № 83 (1783): 662. (Moskovskie vedomosti, No. 83 (1783): 662).

${ }^{18}$ Московские ведомости, № 96 (1783): 765. (Moskovskie vedomosti, No. 96 (1783): 765).

${ }^{19}$ Роспись российским книгам, 31. (Rospis' rossiiskim knigam, 31).

${ }^{20}$ Рукописи Аничкова и библиотека сгорели при пожаре в его доме в середине 1780-х гг.; см.: М. П. Лепехин, “Аничков,” Словарь русских писателей XVIII века, вып. 1 (Ленинград: Наука, Ленинградское отделение, 1988), 33. (М. P. Lepekhin, “Anichkov,” Slovar' russkikh pisatelei XVIII veka,
} 
типографии Московского университета при Новикове выходило немало изданий, подписанных именем Аничкова - труды по арифметике, ${ }^{21}$ геометрии, ${ }^{22}$ алгебре ${ }^{23}$ и фортификации, ${ }^{24}$ а также слова, произнесенные на университетских Торжественных собраниях. ${ }^{25}$ Тем не менее, компиляция 1782 - это единственное его сочинение на латыни.

Поиск возможной связи книги Аничкова с анонимным двухтомником заставил нас еще раз пристально посмотреть на книги из Научной библиотеки Московского университета. Было выявлено несомненное сходство некоторых томов. $^{26}$ И трактат Аничкова, и двухтомник существуют в переплетах из гладкой светло-коричневой телячьей кожи и имеют одинаковые форзацы с цветным печатным орнаментом и печатные же наклейки на корешке “Библиотека древних языков" с вписанным номером, а также номером “22.3” на последнем форзаце, сделанным одной и той же рукой орешковыми чернилами.

Библиотека древних языков - традиционный раздел книгохранилищ духовных образовательных учреждений. Благодаря стечению обстоятельств нам удалось выяснить, откуда в библиотеку Московского университета поступили книги. На форзаце 2а одной из них сохранился плохо различимый инскрипт на смеси русского и латинского языков, в котором, к счастью, удалось полностью прочесть не самое распространенное имя. Это дарственная надпись некоему Диомиду Каллистову, сделанная не слишком уверенным почерком последней четверти XVIII столетия. Диомид Герасимович Каллистов нашелся по списку 1782 года среди учеников класса “Аналогия” во Владимирской духовной

vyp. 1 (Leningrad: Nauka, 1988), 33).

${ }^{21}$ Д. С. Аничков, Теоретическая и практическая арифметика: В пользу и употребление юношества. Издание третие (Москва: тип. Комп. Тип., 1786). (D. S. Anichkov, Teoreticheskaia i prakticheskaia arifmetika: V pol'zu i upotreblenie iunoshestva. Izdanie tretie (Moscow: tip. Komp. Tipogr., 1786)).

${ }^{22}$ Аничков, Теоретическая и практическая геометрия: В пользу и употребление не токмо юношества, но и тех, кои упражняются в землемерии, фортификации и артиллерии (Москва: Унив. тип. У Н. Новикова, 1780). (Anichkov, Teoreticheskaia i prakticheskaia geometriia: V pol'zu $i$ upotreblenie ne tokmo iunoshestva, no i tekh, koi uprazhniaiutsia $v$ zemlemerii, fortifikatsii I artillerii (Moscow: Univ. tip., u N. Novikova, 1780)).

${ }_{23}$ Аничков, Начальныя основания алгебры, или арифметики литеральной: Служащия для удобнейшаго и скорейшаго вычисления как арифметических, так и геометрических задач, в пользу и употребление российскаго юношества, упражняющагося в математических науках (Москва: Унив. тип. У Н. Новикова, 1781). (Anichkov, Nachal'nye osnovaniia algebry, ili arifmetiki literal'noi: Sluzhashchaia dlia udobneishago i skoreishago vychisleniia kak arifmeticheskikh, tak i geometricheskikh zadach, $v$ pol'zu i upotrebleniia rossiiskogo iunoshestva, uprazhniaiushchegosia $v$ matematicheskikh naukakh (Moscow: Univ. tip., u N. Novikova, 1781)).

${ }^{24}$ Аничков, Начальныя основания фортификации, или военной архитектуры: Служащия в пользу и употребление российскаго юношества, упражняющагося в математических науках (Москва: Унив. тип. у Н. Новикова, 1787). (Anichkov, Nachal'nye osnovaniia fortifikatsii, ili voennoi arkhitektury: Sluzhashchiia $v$ pol'zu I upotreblenie rossiiskago iunoshestva, uprazhniaiushchagosia $v$ matematicheskikh naukakh (Moscow: Univ. tip., u N. Novikova, 1787)).

${ }^{25}$ Аничков, Слово о превратных понятиях человеческих, происходящих от излишняго упования, возлагаемаго на чувства (Москва: Унив. тип. у Н. Новикова, 1779). (Anichkov, Slovo o prevratnykh poniatiiakh chelovecheskikh, proiskhodiashchikh ot izlishnikh upovanii, vozlagaemykh na chuvstva (Moscow: Univ. tip., u N. Novikova, 1779)); Аничков, Слово о разных способах, теснейший союз души с телом изъясняющих (Москва: Унив. тип., у Н. Новикова, 1783). (Anichkov, Slovo o raznykh sposobakh, tesneishii soiuz dushi s telom iz'iasniaiushchikh (Moscow: Univ. tip., u N. Novikova, 1783)).

${ }^{26}$ Напомним, что все три книги до проведения исследования и написания настоящей статьи имели в библиотеке разные шифры. 


\section{семинарии. $^{27}$}

Иными словами, можно утверждать, что компиляция 1782 года и анонимный латинский двухтомник, если и не составляли части одного издания, то входили в некий комплект, предназначавшихся ученикам духовного училища. Что, тем не менее, не предопределяет решения вопроса об их авторстве.

Замечательно, однако, что существует описание трактата Д. С. Аничкова Annotationes in logicam et metaphysicam..., в котором сказано, что он состоит не из одного, а из нескольких томов. В электронном каталоге Библиотеки Иностранной литературы как сочинение Аничкова указаны безымянные вторая и третья части, входящие в один конволют с изданием 1782 г.; по тем же данным, конволют происходит из собрания еще одного духовного училища - Московской Перервинской семинарии. ${ }^{28}$

Сведения о том, что у Аничкова было сочинение, состоявшее из трех томов, находим в труде архимандрита Гавриила (Воскресенского). Но историк философии пишет о труде, в названии которого вновь к логике и метафизике присоединена космология: “Он сочинил и напечатал в Москве 1782 г. на латинском языке в 3 книжках для философских лекций своих дополнения к Баумейстеровой логике, метафизике и космологии под названием Annotationes in logicam, metaphysicam et cosmologiam. ${ }^{29}$ Эта фраза, однако, представляет собой дословное заимствование из Словаря И. М. Снегирева. ${ }^{30}$ В свою очередь, источником для Снегирева, вероятно, могла послужить биографическая справка, помещенная в собрании речей профессоров Московского университета, где без указания года говорится о трех изданных под этим названием книгах, ${ }^{31}$ или, что вероятнее, еще более ранние сведения митрополита Евгения (Болховитинова), помещенные им в неоконченном “Новом опыте исторического словаря." ${ }^{2}$ На чем

${ }^{27}$ Н. Ф. Малицкий, История Владимирской духовной семинарии, вып. 3: Списки воспитанников. 1750-190о г., сост. Н. Малицкий (Москва: Печатня А. И. Снегиревой, 1902), 12. (N. F. Malitskii, Istoriia Vladimirskoi dukhovnoi seminarii, vyp. 3 Spiski vospitannikov. 1750-190o г., sost. N. Malitskii (Moscow: Pechatnia A. I. Snegirevoi, 1902), 12). Шестнадцатилетний на тот момент сын священника Диомид Каллистов был в дальнейшем преподавателем духовного училища и священником села Мошок, расположенном почти ровно посередине пути из Владимира в Муром.

${ }^{28}$ Annotationes in logicam et metaphysicam, Library of Foreign Literature (Moscow), accessed February 3 .2021, https://catalog.libfl.ru/Record/REDKOSTJ 2112\#libfldescription. Добавим сюда сведения о книгах из Московской Духовной академии и из библиотеки Киево-Печерской лавры, и мы получим тот круг, где имели хождение интересующие нас издания.

${ }^{29}$ Гавриил (Воскресенский), архим., История философии. Ч. 6 (Казань: Унив. тип., 1840), 73. (Gavriil (Voskresenskii), arkhim., Istoriia filosofii. Ch. 6 (Kazan': Univ. tip., 1840), 73).

$3^{\circ}$ И. М. Снегирев, Словарь русских светских писателей, соотечественников и чужестранцев, писавших в России, служащий дополнением к Словарю писателей духовного чина, составленному митрополитом Евгением. Т. 1 (Москва: Унив. тип., 1838), 13. (I. M. Snegirev, Slovar' russkikh svetskikh pisatelei, sootechestvennikov $i$ chuzhestrantsev, pisavshikh v Rossii, sluzhashchii dopolneniem $k$ Slovariu pisatelei dukhovnogo china, sostavlennomu mitropolitom Evgeniem. T. 1 (Moscow: Univ. tip., 1838), 13).

${ }^{31}$ Речи, произнесенные в торжественных собраниях Императорского Московского университета русскими профессорами оного, с краткими их жизнеописаниями. Изданы Обществом любителей российской словесности. Ч. 2. (Москва: Унив. тип., 1820), 5. (Rechi, proiznesennye v torzhestvennykh sobraniiakh Imperatorskogo Moskovskogo universiteta russkimi professorami onogo, s kratkimi ikh zhizneopisaniiami. Izdany Obshchestvom liubitelei rossiiskoi slovesnosti. Ch. 2 (Moscow: Univ. tip., 1820), 5).

$3^{2}$ Евгений (Болховитинов), митр., “Новый опыт исторического словаря о российских писателях, природных и чужестранных, умерших и живых,” Друг просвещения, № 3 (1805): 197. (Evgenii 
основывался ученый митрополит, установить невозможно, но вполне вероятно, что он как современник, а также, как непосредственный участник московского книгопечатания $1780-\mathrm{x}$ гг. ${ }^{33}$ мог знать об авторстве сочинения доподлинно.

Приходится признать, что приводимое в многочисленных работах и справочниках название, в котором упоминаются сразу и логика, и метафизика, и космология, представляет собой контаминацию названий трех различных томов, а автором действительно оказывается Д. С. Аничков. С одной стороны, два анонимных тома, напечатанные, как мы установили, в 1783 году, не имеют признаков, которые объединяли бы их с сочинением Аничкова в одно целое, с другой стороны, логика и метафизика обозначены на титульном листе и в цензорском разрешении книги 1782 года, которая посвящена только логике, а метафизики не касается. С другой стороны, известно, что в XVIII столетии “невозможно было преподавать одну лишь логику, ибо логика неизменно преподавалась публичным профессором логики и метафизики обязательно в комбинации с метафизикой."34

Но почему на титульном листе не обозначена космология? Похоже, дело в том, что спустя четверть века после выхода в свет труда Аничкова, не многие могли точно сказать, что именно тот понимал под метафизикой, и почему охотно повторяемое название Annotationes in logicam, metaphysicam et cosmologiam просто не имеет смысла.

В статье Русского биографического словаря говорится как об общепринятой точке зрения, что трактат Д.С. Аничкова служит “толкованием и вместе дополнением к трудам Ф. Баумейстера.” 35 Практически во всех статьях, посвященных профессору Московского университета, рассматривается зависимость философских воззрений и лекционных курсов Аничкова от сочинений и взглядов этого немецкого философа. Труды Баумейстера и основанные на них пособия были весьма популярны и в Московском университете, и, как показывают каталог книг Московской Духовной академии и сохранившиеся экземпляры, в духовных училищах. ${ }^{36}$ Сочинения немецкого философа неоднократно печатались на латыни и в русских переводах, в том числе и в качестве учебных пособий в типографии Московского университета. ${ }^{37}$

(Bolkhovitinov), mitr., "Novyi opyt istoricheskogo slovaria o rossiiskikh pisateliakh, prirodnykh i chuzhestrannykh, umershikh i zhivykh," Drug prosveshcheniia, № 3 (1805): 197).

${ }^{33}$ Будущий ученый иерарх в 1780-х гг. был знаком с членами литературного кружка Н. И. Новикова и подрабатывал корректором у книгоиздателя М. П. Пономарева; см.: Православная энциклопедия, t. 17 (Москва: Церковно-науч. центр Православная энциклопедия, 20о8), 63. (Pravoslavnaia éntsiklopediia, t. 17 (Moscow: Tserkovno-nauch. sentr Pravoslavnaiia Ėtsiklopediia, 20o8), 63).

${ }^{34}$ А. Н. Круглов, “Преподавание логики в Императорском Московском университете XVIII века," Логико-философские штудии, t. 18 (№ 2) (2020), 164. (A. N. Kruglov, "Prepodavanie logiki v Imperatorskom Moskovskom universitete XVIII veka," Logiko-filosofskie shtudii, t. 18 (No. 2) (2020), 164). ${ }^{35}$ Русский Библиографический Словарь, t. 2, 149 (Russkii biograficheskii slovar', t.2, 149).

${ }^{36}$ Ср.: Круглов, Преподавание логики, 168 и след. (Kruglov, Prepodavanie logiki, 168).

${ }^{37}$ Укажем лишь издания, вышедшие у Н. И. Новикова: Ф. Х. Баумейстер, Християна Бауместера Логика. Перевод с латинскаго Александра Павлова. Издание второе (Москва: тип. Комп. Типогр., 1787). (F. Kh. Baumeister, Khristiiana Baumeistera logika. Perevod s latinskago Aleksandra Pavlova. Izdanie vtoroe (Moscow: tip. Komp. Tipogr., 1787)); Баумейстер, Нравоучительная философия: Содержащая естественное право, этику, политику, экономию и другие вещи, для знания нужные u полезные. Перевел с латинскаго языка профессор Дмитрий Синьковский (Москва: тип. Комп. Типогр., 1788). (Baumeister, Nravouchitel'naia filosofiia, soderzhashchaia estestvennoe parvo, etiku, 
Согласно Баумейстеру, который следовал классификации Христиана Вольфа, метафизика подразделяется на четыре части: онтологию, космологию, психологию и богословие..$^{38}$ Очевидно, что два “анонимных" тома соответствуют двум первым преподаваемым разделам метафизики. ${ }^{39}$

Таким образом, в настоящее время издание должно быть описано следующим образом:

Annotationes in logicam et metaphysicam ex variis probatissimis auctoribus excerptae et usibus Rossicae juventutis una cum parte polemica et variis exercitationibus, ex logica disputatrice selectis, adornatae a collegiorum assessore, logices, metaphysices et matheseos purae in Universitate Imperiali Mosquensi professore publico ordinario Demetrio Anitschcow. - Mosquae [Moscow]: Impensis N. Novicow et societatis: In Typographia Universitatis apud N. Novicow, 1782-[1783]. - 16 см.

[Ч. 1]. - 1782. - 221 с., [2] л. ил.

[Ч. 2, т. 1]: Annotationes in metaphysicam, et quidem I. In Ontologiam. [1783]. - $242 \mathrm{c}$.

[Ч. 2, т. 2]: II. Annotationes in Cosmologiam. - [1783]. - 144 c.

Добавим в заключение, что историки философии, а также историки образования получают новый источник сведений и о преподавании метафизики в Московском университете и духовных училищах в последние годы XVIII столетия, и о философских воззрениях известного самостоятельностью суждений профессора Дмитрия Сергеевича Аничкова.

politiku, ekonomiiu i drugie veshchi dlia znaniia nuzhnye i poleznye. Perevel s latinskago iazyka professor Dmitrii Sin'kovskii (Moscow: tip. Komp. Tipogr., 1788)); Баумейстер, Христиана Баумейстера Метафизика. Перевод с латинскаго Александра Павлова вновь высмотрен и на многих местах исправлен профессором Дмитрием Синьковским. Издание второе (Москва: Унив. тип., у Н. Новикова, 1789) (Baumeister, Khristiana Baumeistera metafisika. Perevod s latinskago Aleksandra Pavlova vnov' vysmotren i na mnogikh mestakh ispravlen professorom Dmitriem Sin'kovskim. Izdanie vtoroe (Moscow: Univ. tip., u N. Novikova, 1789)). Добавим сюда же приписывавшееся Баумейстеру издание: Разумная беседа, или Собрание важных, острых и замысловатых изречений. Переведена с французскаго языка на российской А. Н. (Москва: Тип. Комп. типогр., 1788). (Razumnaia beseda, ili sobranie vazhnykh, ostrykh i zamyslovatykh izrechenii. Perevedena s frantsuzskago iazyka na rossiiskii A. N. (Moscow: tip. Komp. Tipogr., 1788)).

${ }^{38}$ Cp.: M. Frid. Christ, Bavmeisteri Avgvsti Gymnasii Gorlicensis Rectoris Institvtiones Metaphysicae: Ontologiam Cosmologiam, Psychologiam Theologiam Denique Naturalem Complexae; Methodo Wolffii Adornatae (Wittenbergae \& Servestae: Zimmermannus, 1738). Исправленные издания под тем же названием выходили в 1754, а затем в 1760 г. Вполне вероятно, что замена institutiones на annotationes как раз и является свидетельством того, что Аничков превращает сочинение Баумейстера в “прибавления” и комментарии к нему.

39 Возможно также, что, случившийся в московском доме профессора пожар стал причиной того, что “замечания” к психологии и богословию, которые назывались бы Annotationes in psychologiam et theologiam, так и не вышли из печати. 